NBER WORKING PAPER SERIES

\title{
HIT HARDER, RECOVER SLOWER? UNEQUAL EMPLOYMENT EFFECTS OF THE COVID-19 SHOCK
}

\author{
Sang Yoon (Tim) Lee \\ Minsung Park \\ Yongseok Shin \\ Working Paper 28354 \\ http://www.nber.org/papers/w28354
NATIONAL BUREAU OF ECONOMIC RESEARCH
1050 Massachusetts Avenue
Cambridge, MA 02138
January 2021

Lee is a reader at Queen Mary University of London. Park is a $\mathrm{PhD}$ candidate at Washington University in St. Louis. Shin is a professor of economics at Washington University in St. Louis and a research fellow at the Federal Reserve Bank of St. Louis. Lee gratefully acknowledges financial support from the British Academy [grant number COV19n201483]. The views expressed herein are those of the authors and do not necessarily reflect the views of the National Bureau of Economic Research.

NBER working papers are circulated for discussion and comment purposes. They have not been peer-reviewed or been subject to the review by the NBER Board of Directors that accompanies official NBER publications.

(C) 2021 by Sang Yoon (Tim) Lee, Minsung Park, and Yongseok Shin. All rights reserved. Short sections of text, not to exceed two paragraphs, may be quoted without explicit permission provided that full credit, including $\odot$ notice, is given to the source. 
Hit Harder, Recover Slower? Unequal Employment Effects of the Covid-19 Shock

Sang Yoon (Tim) Lee, Minsung Park, and Yongseok Shin

NBER Working Paper No. 28354

January 2021

JEL No. E24,J15,J16,J21

\section{ABSTRACT}

The destructive economic impact of the Covid-19 pandemic was distributed unequally across the population. Gender, race and ethnicity, age, education level, and a worker's industry and occupation all mattered. We analyze the initial negative effect and the lingering effect through the recovery phase across demographic and socio-economic groups. The initial negative impact on employment was larger for women, minorities, the less educated, and the young, even after accounting for the industries and occupations they worked in. By November 2020, however, the differential impact between men and women, and between education and age groups has vanished. Across race and ethnic groups, Hispanics and Asians were the worse hit but made up for most of the lost ground, while the initial impact on Blacks was smaller but recovery slower.

Sang Yoon (Tim) Lee

Queen Mary University of London

Mile End Road

E1 4NS London

United Kingdom

and CEPR

sylee.tim@qmul.ac.uk

Minsung Park

Washington University in St. Louis

1 Brookings Dr

CB 1208

Saint Louis, MO 63130

USA

park.m@wustl.edu
Yongseok Shin

Department of Economics

Washington University in St. Louis

One Brookings Drive

St. Louis, MO 63130

and NBER

yshin@wustl.edu 
As late as February 2020, the US labor market was booming. The unemployment rate stood at 3.5 percent, a record low since December 1969. Then Covid-19 struck out of the blue, with an unprecedented speed and ferocity. US unemployment spiked to 14.7 percent in April, although it came down to 6.7 percent by November.

Covid-19's attack on the labor market was multi-faceted, but broadly materialized through two channels. The first was through the voluntary reduction in consumer and business activities, especially contact-intensive ones, out of fear of infection. The other was through governments' containment policies, such as various social distancing measures and lockdowns of large swaths of the economy, especially targeted toward jobs categorized as "non-essential."

Jobs differ by contact intensity and the ease with which they can be performed remotely, in addition to their essential or non-essential classification (Hensvik et al., 2020; Aum et al., 2020b). Warnings abound that the economic toll of the pandemic would be unevenly distributed and exacerbate pre-existing inequality across demographic and socio-economic groups, because women and minorities were more likely to work in the more vulnerable jobs (Alon et al., 2020; Blundell et al., 2020). At the onset of the pandemic, near real-time data revealed that women lost more jobs and were forced to work less, both in the US and the UK (Cajner et al., 2020; Adams-Prassl et al., 2020a,b). It also became apparent that minorities were disadvantaged not only because of the types of jobs they worked in, but also because they were more likely to face employment reductions even within the same jobs (Montenovo et al., 2020; Cowan, 2020; Gezici and Ozay, 2020).

In this paper, we analyze how the initial economic impact of the pandemic and the subsequent recovery differed along numerous dimensions, including gender, race and ethnicity, educational attainment, industry, occupation, and state-level policies and state-wide Covid-19 infections. The main contribution to the literature is our analysis of the recovery phase through November 2020, as many researchers have documented the early impact of the pandemic in the spring of $2020 .^{1}$

Our main findings can be summarized as follows.

- Women, minorities, the less educated, and the young were hit harder by the pandemic, which was partly an industry-occupation composition effect-e.g., their disproportionate presence in leisure/hospitality and other service industries. In particular, Hispanics' employment loss was entirely due to this composition effect.

- The demographic and socio-economic groups that were hit harder initially have also recovered faster, especially once industry and occupation effects are controlled for.

\footnotetext{
${ }^{1}$ The paper most closely related to ours is Couch et al. (2020), which compares the experience of Blacks, Hispanics and Asians relative to whites, from April to June 2020. Our results complement theirs with data from later months, but we also find new evidence for the spring.
} 
- More generally, the pandemic's differential effects across gender, age and education have more or less vanished by November, whether or not industry and occupation effects are controlled for.

- One exception is Black workers. They were the least affected by the initial shock among all racial groups, but their recovery is the slowest, even when industry and occupation effects are controlled for.

- In April 2020, local employment was hit hard in states which had high levels of infection, with containment policies having no significant effect. But by November, the severity of the epidemic has no discernible effect on employment, once we control for containment policies.

We now describe the data and our methodology (Sections 1 and 2), before discussing the results in more detail (Section 3).

\section{Data}

We use the monthly Current Population Survey (CPS) from the Bureau of Labor Statistics (BLS). We limit the sample to 20 to 65 year-olds and consider four variables of interest: (i) unemployment, (ii) jobless unemployment, (iii) furlough or recall unemployment, and (iv) non-participation (not in the labor force). Unemployment and non-participation are directly recorded by the BLS. Jobless unemployment and recall unemployment are sub-categories of unemployment. The identification of jobless unemployed and recall unemployed relies on the definition in Hall and Kudlyak (2020). Respondents are asked if they are currently on layoff. If yes, they are asked whether they were given a return date to work or any indication that they would be called back to work within the next 6 months. If the answer is again yes, they are asked whether they can return if/when recalled. If the answer to this last question is also yes, then the respondent is classified as recall unemployed, i.e., one who has a job to return to. On the other hand, if a respondent did not work during the survey week, is not currently on layoff, and has been actively looking for work, then he or she is classified as jobless unemployed. ${ }^{2}$

For demographic and socioeconomic characteristics, we consider gender (male, female), race and ethnicity (white, Black, Hispanic, Asian), age (20-35, 36-50, 51-65), education (high school or less, some college, 4-year college or more), industry, occupation, and urban/rural residence. We classify industries and occupations into 14 and 11 categories respec-

\footnotetext{
${ }^{2}$ The union of recall unemployment and jobless unemployment is smaller than unemployment, but the difference is small.
} 
tively, based on Major Industry Recodes and Major Occupation Group Recodes provided by the BLS. The CPS has information about whether respondents live in a central city, outside a central city but still in a metropolitan area, or outside a metropolitan area.

We also consider infection levels by state, and state governments' policy responses to the pandemic. Daily case counts from the Centers for Disease Control and Prevention (CDC) COVID Data Tracker are used to calculate the number of cases per 1,000 people. ${ }^{3}$ We group states into low, medium, and high risk, with equal number of states in each category. In addition, we group states by their policy responses to Covid-19 following the Oxford Covid-19 Government Response Tracker (OxCGRT). ${ }^{4}$ OxCGRT reports 14 timevarying indicators to measure the policy responses of several governments, including the 50 US states and the District of Columbia. Each indicator is classified as "containment and closure," "economic response," "health systems," or "miscellaneous," and is used for creating a score for the overall government response (Hale et al., 2020). ${ }^{5}$ Based on these scores, states are grouped into three categories: (i) robust response states, which adopted and maintained robust containment, testing and contact tracing policies, (ii) rapid rollback states, which adopted a robust response initially but then rolled back policies relatively quickly, and (iii) low response states, which never adopted particularly restrictive containment measures or robust testing and contact tracing systems.

\section{Estimation}

The panel dimension of the CPS is short, so it is not possible to track individuals over the course of a year. ${ }^{6}$ We instead estimate the following individual-level linear regression model to capture the factors correlated with the labor market impact of the pandemic:

$$
Y_{i t}^{s}=\alpha+\alpha_{1} \chi_{t=2020}+X_{i t}^{s}\left[\beta+\beta_{1} \chi_{t=2020}\right]+\epsilon_{i t}^{s} .
$$

We run the regression separately for $s=4$ (April) or 11 (November), and $t=2019$ or 2020. April 2020 was when the pandemic's economic impact was at its peak, and November 2020 was the most recent sample available from the CPS to gauge the recovery process.

\footnotetext{
${ }^{3}$ https://covid.cdc.gov/covid-data-tracker

${ }^{4}$ www.bsg.ox.ac.uk/research/research-projects/coronavirus-government-response-tracker

${ }^{5}$ The online repository provides detailed coding information: https://github.com/OxCGRT/ covid-policy-tracker/blob/master/documentation/codebook.md.

${ }^{6}$ The CPS has outgoing rotation samples and the BLS interviews each household for 4 consecutive months. The household leaves the sample for the next 8 months and returns for another 4 months. The sample collecting process happens every month, so only a quarter of the sample can be tracked from one month to the next.
} 
Comparing the same months of 2019 and 2020 is informative about the economic effect of the pandemic, seasonally adjusted. The dependent variable $Y_{i t}^{s}$ is a binary variable of individual $i$ 's employment status in month $s$ in year $t$, and we run separate regressions for non-participation, unemployment, jobless unemployment, and recall unemployment.

The vector of regressors $X_{i t}^{s}$ includes group dummies on gender, race and ethnicity, education, age, industry, occupation, and geographic location. The location variables include (i) urban/rural residence, (ii) state-wide new Covid-19 cases per 1,000 people during the preceding month (to be precise, cumulative counts through April 15 for the April regression and October 15 to November 15 for the November regression, since CPS interviews are conducted during the week that contains the 19th of each month), and (iii) the state government's policy response. For April, states policy responses are categorized only as robust or low response (because there was no rapid-rollback state), while November further includes rapid-rollback states.

The indicator function $\chi_{t=2020}$ equals one if the year is 2020 and zero otherwise. In this specification, $\beta_{1}$ is the parameter of interest, which captures the differential effect of the pandemic on each demographic and socioeconomic group.

\section{Results}

\subsection{Unemployment by Gender, Race/Ethnicity, Age and Educa- tion}

Before we report the estimation results, we first show the evolution of labor market outcomes as a whole, and then by gender, race and ethnicity, age and educational attainment.

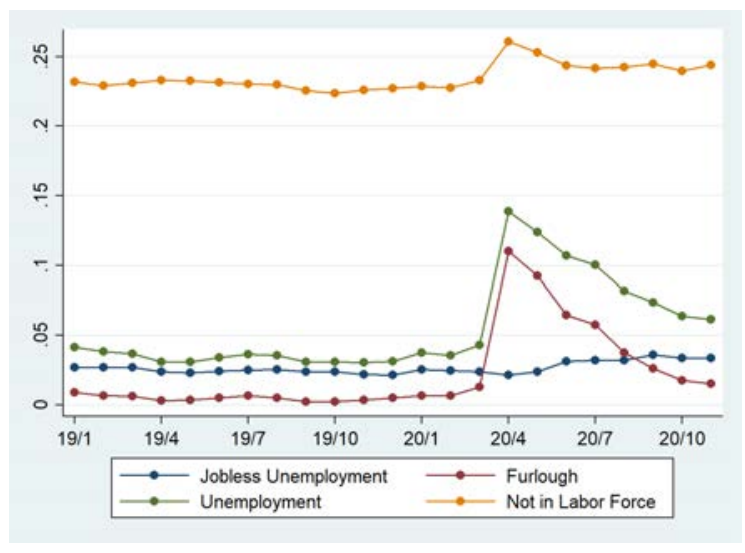

Figure 1: Aggregate Unemployment and Non-employment

Figure 1 plots the non-participation rate ("Not in Labor Force"), unemployment rate, jobless unemployment rate and recall unemployment rate from January 2019 onward. The 


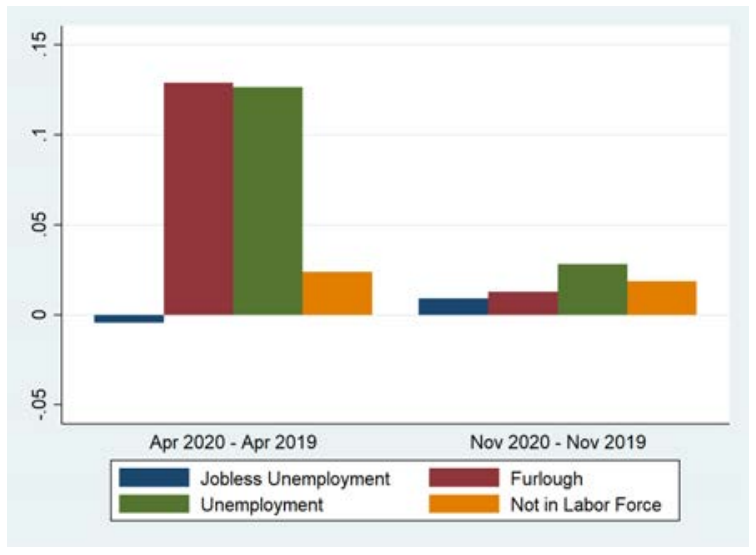

(a) Female

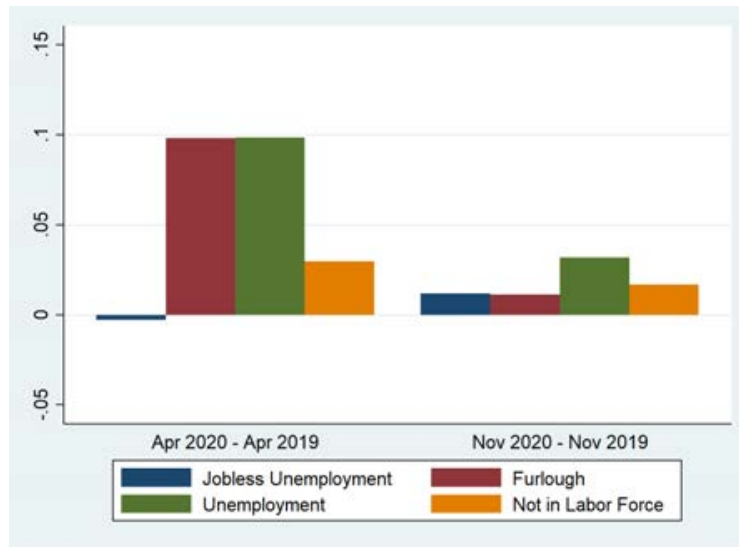

(b) Male

Figure 2: Labor Market Impact of Covid-19 by Gender

pandemic hit the economy hard in April 2020, and the economy has since been recovering towards the pre-pandemic level. Note that the unemployment jump is almost entirely accounted for by recall unemployment, which came down fast in the following months (but still 1.2 percentage points higher in November 2020 than in November 2019). This is broadly consistent with the findings of Hall and Kudlyak (2020). On the other hand, the jobless unemployment rate began to rise only in July 2020, and more than one-third of the current elevated level of the unemployment rate is explained by higher jobless unemployment (1.2 p.p. out of 3.1 p.p.). The pace of recovery has slowed markedly since October 2020. At the time of writing, the US economy experienced net job losses in December 2020, and the unemployment rate in December was the same as the November rate, 6.7 percent.

Figure 1 also shows that some workers dropped out of the labor force (instead of entering unemployment) when the pandemic hit. The non-participation rate increased by 3.1 percentage points between March and April 2020. This is the largest monthly increase ever recorded. For comparison, after the onset of the Great Recession, it took nearly 6 years for the non-participation rate to rise by 3.1 percentage points (from December 2007 to October 2013). The recovery in the non-participation rate has stalled since June 2020, and is still 1.8 percentage points higher in November 2020 than in November 2019.

Figure 2 shows the impact of the pandemic on the employment status of men and women. In the left panel, the first four bars show the change in jobless unemployment, recall unemployment (furlough), unemployment and non-participation rates between April 2019 and April 2020 for women, capturing the peak impact of the pandemic. The next four bars are the changes in these four rates between November 2019 and November 2020. The right panel is for men. Comparing the two panels, we see that women were hit harder by the pandemic than men (April unemployment up by 12.7 vs. 9.9 p.p.), all driven by the rise in 
recall unemployment. This was a unique phenomenon: Typically men are more adversely affected by recessions than women (Alon et al., 2020). Non-participation, on the other hand, rose slightly more for men than for women in April (3.0 vs. 2.4 p.p.). But by November 2020, this gender gap completely disappeared. If anything, it reversed: men's unemployment rate in November 2020 is up by 3.2 p.p. relative to November 2019, but women's by 2.8 percent. (The year-on-year change in the non-participation rate is now slightly higher for women than for men in November: 1.9 vs. 1.7 p.p.) In summary, the pandemic hit women harder initially, but what remains of the pandemic's effect on unemployment is almost the same for men and women. We again see that the initial impact and the ensuing recovery in unemployment all came through recall unemployment. There was no significant gender differential in the pandemic's impact on the non-participation rate.

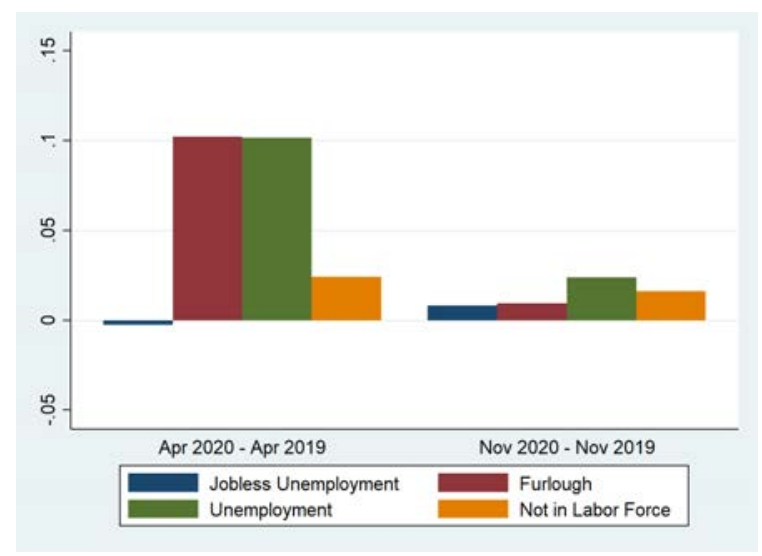

(a) White

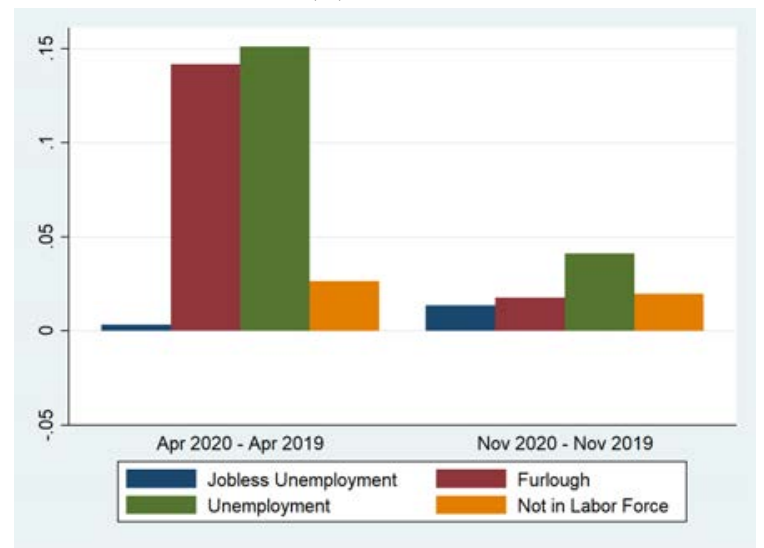

(c) Hispanic

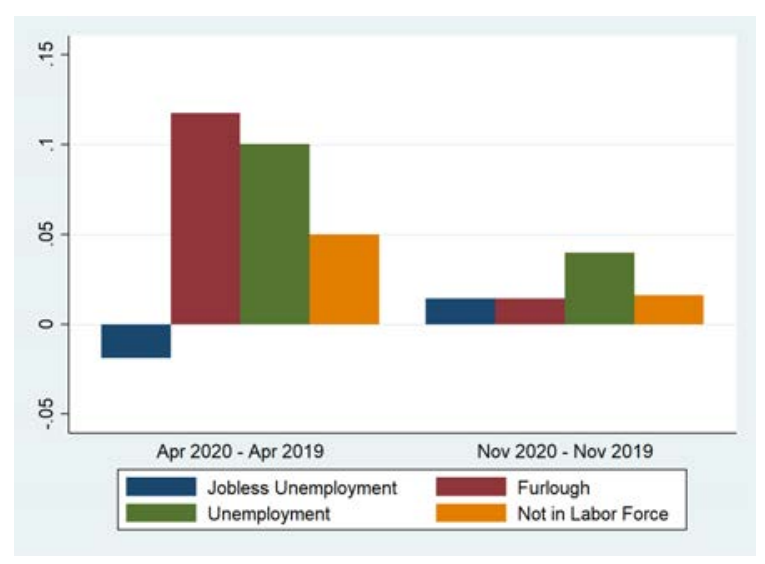

(b) Black

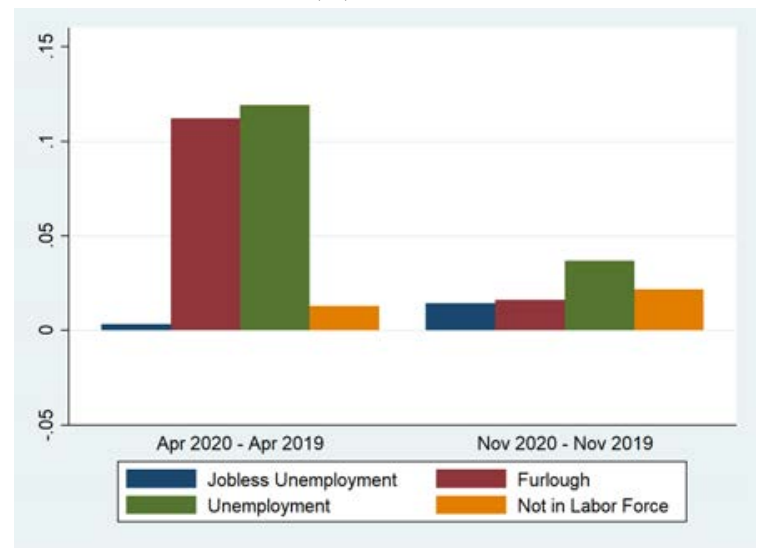

(d) Asian

Figure 3: Labor Market Impact of Covid-19 by Race/Ethnicity

Figure 3 shows the employment impact across race and ethnicity. Comparing the yearon-year change in the unemployment rate in April, it is clear that Hispanics were hit harder than any other group (unemployment up by 15.1 p.p.), followed by Asians (12.0 p.p). Blacks' 
unemployment rose the least among all groups, including whites' (10.0 vs. 10.2 p.p.), but their non-participation rate rose by 5 p.p., double the increase for whites and Hispanics. Comparing the year-on-year change in November, we see that whites' unemployment rate in November 2020 is only 2.4 p.p. higher than in November 2019, a smaller negative effect compared to Blacks' 4.0, Hispanic's 4.1 and Asians' 3.7 p.p. year-on-year change in unemployment. It is clear that minorities were hit harder economically by the pandemic, and they are also recovering more slowly. The remaining effect on the non-participation rate is also larger for minorities, although the magnitude is smaller. The year-on-year change in the November non-participation rate is 2.0 and 2.2 p.p. for Hispanics and Asians, compared to 1.6 p.p. for both Blacks and whites.

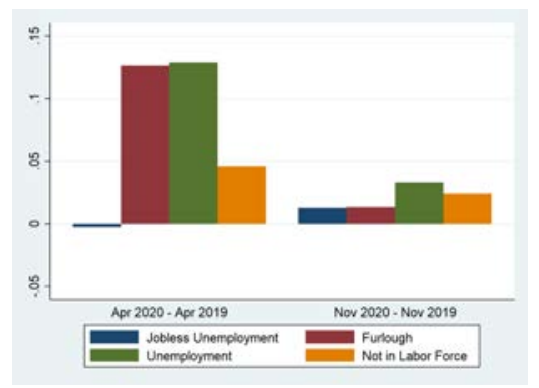

(a) Age 20 to 35

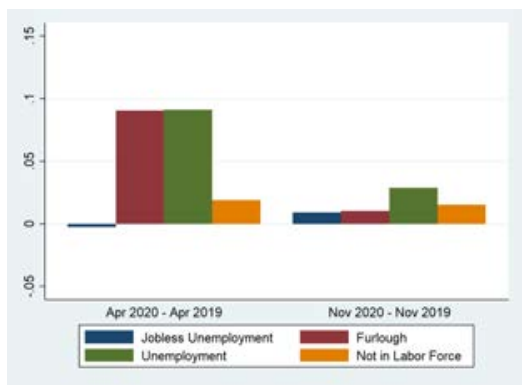

(b) Age 36 to 50

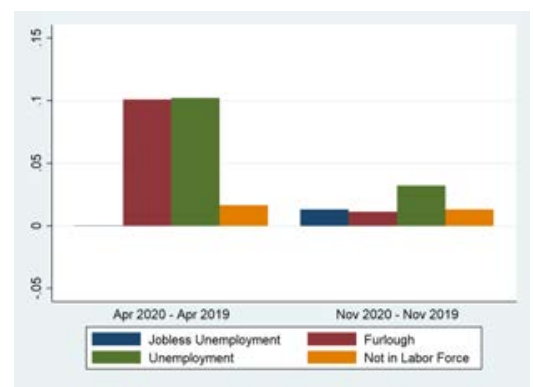

(c) Age 51 to 65

Figure 4: Labor Market Impact of Covid-19 by Age

Figure 4 shows how the employment outcomes of different age groups were affected by the Covid-19 shock. Clearly, the young (20 to 35 years old) were hit the hardest in April 2020: their year-on-year increase in the unemployment rate and the non-participation rates were 12.9 p.p. and 4.6 p.p., respectively. However, by November 2020, the unemployment effect of the pandemic are fairly similar across all three age groups, except that the youngest group's non-participation rate has not recovered as much.

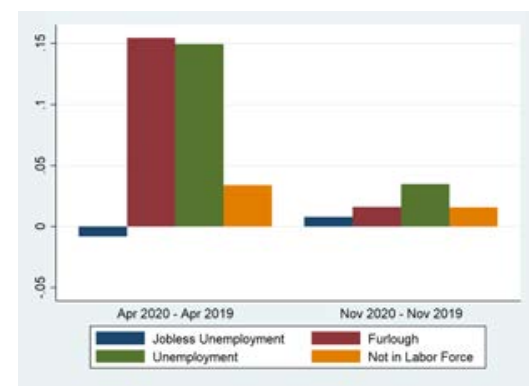

(a) High School or Less

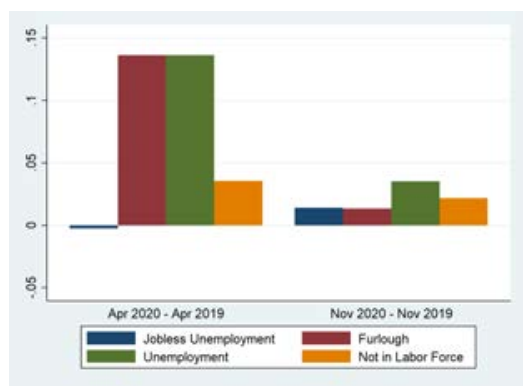

(b) Some College

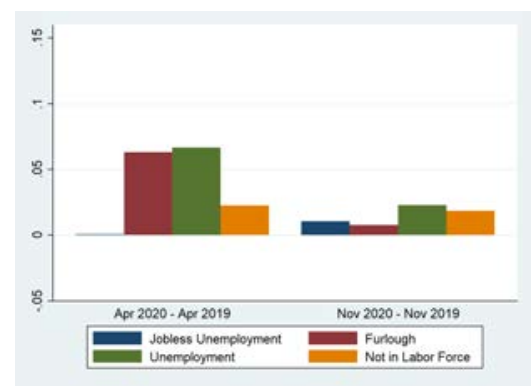

(c) Bachelor Degree or More

Figure 5: Labor Market Impact of Covid-19 by Education Attainment

Figure 5 shows the negative employment effects by educational attainment: high school 
graduates or those with less education, those with some college education but without a 4-year degree, and those with a 4-year degree or more. Consistent with the general findings in the labor literature (e.g., Lee et al., 2015), the patterns for high school graduates and some college are broadly similar. High school graduates' unemployment rate was higher by 15.0 p.p. in April 2020 than in April 2019, and some college's by 13.6 p.p., while college graduates' were only 6.7 p.p. higher. (The magnitude is smaller, but the pattern is similar for the non-participation rate.) By November, all groups experienced significant recovery, again due to the drop in recall unemployment. The unemployment rate in November 2020 is higher than in November 2019 by 3.5 p.p. for high school graduates and some college, and by 2.3 p.p. for college graduates. The picture is clear that those with more education were economically less affected by the pandemic.

\subsection{Estimation Results}

We now turn to the estimates from equation (1). Although the figures in the previous section offer a snapshot of the unequal employment effect of the pandemic across demographic and socio-economic groups, the effects shown there were confounded by the overlapping compositions across those groups, as well as their distribution across industries, occupations, and geographic areas that were all hit differently by the pandemic. Regression (1) can isolate the effect that is specific to each group, which is captured by the coefficient $\beta_{1}$.

The estimated $\beta_{1}$ for each group (other than the reference group, by construction) is reported in Table 1 for the year-on-year change in April 2020. A significant positive estimate means that the employment outcomes of a given group were worse than the reference group's.

Consistent with the results in Section 3.1, we find that the negative employment effects at the peak of the pandemic was larger for women (than men), for Hispanics and Asians (than whites and Blacks), for the less educated, and for young workers, controlling for all other factors. However, there are two remarkable findings. First, Blacks were significantly less likely to be unemployed than whites, once other factors are controlled for. Second, despite the larger point estimate, Hispanics were not significantly more likely to be unemployed than whites (at the 10-percent significance level), once industry, occupation, and other effects are controlled for, implying that Hispanics were economically exposed to the pandemic by virtue of the types of jobs that they held.

By industry, we see that leisure/hospitality, and other services were hit the hardest, while service, construction and production occupations suffered more than other occupations.

The final few rows of Table 1 show how state-level policy responses and the extent of the pandemic in the preceding month are correlated with employment outcomes. Somewhat surprisingly, state-level containment policies have no significant effect on unemployment or 
Table $1-$ April

(1) (2) (3) (4)

Jobless Unemployment Furlough Unemployment Not in Labor Force

[Gender] Male

Female $\times 20 / 4$

$-0.00109$

$(0.00278)$

$\begin{array}{ll}0.0332^{* * *} & 0.0333^{* * *} \\ (0.00415) & (0.00504)\end{array}$

0.000424

$(0.00415) \quad(0.00504)$

(0.00213)

[Race] White

Black $\times 20 / 4$

$-0.0113^{* *}$

$-0.0127^{*} \quad-0.0230^{* * *}$

$0.00616^{*}$

(0.00521)

(0.00674)

(0.00851)

(0.00364)

Hispanic $\times 20 / 4$

0.00543

0.00397

$0.0127^{*}$

(0.00586)

(0.00701)

0.00169

(0.00364)

0.0107

$0.0165^{* *}$

(0.00271)

$\quad$ Asian $\times 20 / 4$

0.00302

(0.00699)

(0.00835)

0.00298

(0.00445)

0.00170

0.00617

(0.00585)

0.00783

(0.00693)

$-0.00334$

(0.00360)

$-0.0301^{* * *}$

$-0.0252^{* * *}$

(0.00283)

College $\times 20 / 4$

0.00343

(0.00579)

(0.00693)

$-0.00467^{*}$

(0.00273)

[Age] Aged 20 to 35

Aged 36 to $50 \times 20 / 4$

$\begin{array}{lrr}-0.00127 & -0.0160^{* * *} & -0.0205^{* * *} \\ (0.00305) & (0.00459) & (0.00558) \\ & & \\ 0.00114 & -0.00829^{*} & -0.0117^{* *}\end{array}$

$-0.00229$

(0.00218)

Aged 51 to $65 \times 20 / 4$

$-0.00829^{*} \quad-0.0117^{* *}$

0.00170 
[Industry] Public administration

Mining $\times 20 / 4$

\begin{tabular}{|c|c|c|c|}
\hline $\begin{array}{c}0.0268 \\
(0.0174)\end{array}$ & $\begin{array}{c}0.0170 \\
(0.0163)\end{array}$ & $\begin{array}{l}0.0559^{* *} \\
(0.0258)\end{array}$ & $\begin{array}{l}0.00925 \\
(0.0138)\end{array}$ \\
\hline $\begin{array}{c}-0.0138^{*} \\
(0.00742)\end{array}$ & $\begin{array}{c}0.0731^{* * *} \\
(0.0108)\end{array}$ & $\begin{array}{c}0.0609^{* * *} \\
(0.0134)\end{array}$ & $\begin{array}{c}0.00172 \\
(0.00552)\end{array}$ \\
\hline $\begin{array}{c}0.00407 \\
(0.00528)\end{array}$ & $\begin{array}{l}0.0660^{* * *} \\
(0.00810)\end{array}$ & $\begin{array}{c}0.0728^{* * *} \\
(0.0102)\end{array}$ & $\begin{array}{l}-0.00224 \\
(0.00465)\end{array}$ \\
\hline $\begin{array}{c}-0.000744 \\
(0.00596)\end{array}$ & $\begin{array}{l}0.0747^{* * *} \\
(0.00860)\end{array}$ & $\begin{array}{c}0.0756^{* * *} \\
(0.0109)\end{array}$ & $\begin{array}{c}0.000684 \\
(0.00474)\end{array}$ \\
\hline $\begin{array}{c}-0.00757 \\
(0.00673)\end{array}$ & $\begin{array}{l}0.0619^{* * *} \\
(0.00997)\end{array}$ & $\begin{array}{c}0.0539^{* * *} \\
(0.0124)\end{array}$ & $\begin{array}{c}-0.000990 \\
(0.00555)\end{array}$ \\
\hline $\begin{array}{c}0.0145 \\
(0.0104)\end{array}$ & $\begin{array}{c}0.0494^{* * *} \\
(0.0119)\end{array}$ & $\begin{array}{c}0.0706^{* * *} \\
(0.0171)\end{array}$ & $\begin{array}{c}0.00495 \\
(0.00768)\end{array}$ \\
\hline $\begin{array}{l}0.000417 \\
(0.00550)\end{array}$ & $\begin{array}{l}0.0186^{* * *} \\
(0.00698)\end{array}$ & $\begin{array}{c}0.0220^{* *} \\
(0.00936)\end{array}$ & $\begin{array}{c}0.0000829 \\
(0.00457)\end{array}$ \\
\hline $\begin{array}{c}0.00407 \\
(0.00480)\end{array}$ & $\begin{array}{l}0.0384^{* * *} \\
(0.00681)\end{array}$ & $\begin{array}{l}0.0444^{* * *} \\
(0.00872)\end{array}$ & $\begin{array}{c}0.00408 \\
(0.00426)\end{array}$ \\
\hline $\begin{array}{c}0.00476 \\
(0.00396)\end{array}$ & $\begin{array}{l}0.0620^{* * *} \\
(0.00649)\end{array}$ & $\begin{array}{l}0.0678^{* * *} \\
(0.00794)\end{array}$ & $\begin{array}{c}0.00181 \\
(0.00396)\end{array}$ \\
\hline $\begin{array}{l}0.0146^{* *} \\
(0.00705)\end{array}$ & $\begin{array}{l}0.245^{* * *} \\
(0.0120)\end{array}$ & $\begin{array}{l}0.274^{* * *} \\
(0.0136)\end{array}$ & $\begin{array}{c}0.0117^{* *} \\
(0.00581)\end{array}$ \\
\hline
\end{tabular}

Leisure and hospitality $\times 20 / 4$ 
Other services $\times 20 / 4$

Agriculture, forestry, fishing, and hunting $\times 20 / 4$

Armed Forces × 20/4

[Occupation] Management, business, and financial

Professional and related $\times 20 / 4$

Service $\times 20 / 4$

Sales and related $\times 20 / 4$

Office and administrative support $\times 20 / 4$

Farming, fishing, and forestry $\times 20 / 4$

Construction and extraction $\times 20 / 4$

Installation, maintenance, and repair $\times 20 / 4$

Production $\times 20 / 4$

$\begin{array}{cccc}0.00738 & 0.134^{* * *} & 0.150^{* * *} & 0.00506 \\ (0.00613) & (0.0125) & (0.0142) & (0.00606) \\ 0.00247 & 0.0153 & 0.0206 & -0.000318 \\ (0.0134) & (0.0132) & (0.0186) & (0.00783) \\ 0.00743 & 0.00180 & 0.00823 & -0.140 \\ (0.00763) & (0.0130) & (0.0127) & (0.264)\end{array}$

$-0.00624^{*}$

(0.00344)

$0.0332^{* * *}$

$0.0260^{* * *}$

$0.00436^{*}$

(0.00453)

(0.00587)

(0.00252)

$-0.00722$

$0.115^{* * *}$

$0.112^{* * *}$

$0.0132^{* * *}$

(0.00480)

(0.00787)

(0.00926)

$(0.00371)$

$-0.0114^{*}$

$0.0668^{* * *}$

$0.0643^{* * *}$

$0.0126^{* * *}$

(0.00586)

$(0.00787)$

$(0.0101)$

(0.00397)

$-0.0105^{* *}$

$0.0395^{* * *}$

$0.0330^{* * *}$

$0.00694^{* *}$

(0.00476)

(0.00643)

(0.00822)

(0.00343)

$-0.0492^{* *}$

$0.0622^{* *}$

0.00959

$-0.00383$

(0.0223)

(0.0256)

(0.0330)

(0.0114)

$0.0147^{*}$

(0.00856)

$0.0881^{* * *}$

$0.111^{* * *}$

0.00693

(0.0122)

(0.0152)

(0.00579)

$-0.0132^{*}$

$0.0573^{* * *}$

$0.0462^{* * *}$

0.00951

(0.00705)

(0.0123)

(0.0146)

(0.00619)

$-0.0163^{* *}$

$0.0922^{* * *}$

$0.0128^{* * *}$ 


\begin{tabular}{|c|c|c|c|c|}
\hline & $(0.00691)$ & $(0.0112)$ & $(0.0134)$ & $(0.00477)$ \\
\hline Transportation and material moving $\times 20 / 4$ & $\begin{array}{l}-0.00136 \\
(0.00733)\end{array}$ & $\begin{array}{l}0.0738^{* * *} \\
(0.00995)\end{array}$ & $\begin{array}{c}0.0784^{* * *} \\
(0.0125)\end{array}$ & $\begin{array}{l}0.0130^{* * *} \\
(0.00488)\end{array}$ \\
\hline \multicolumn{5}{|l|}{ [Policy] Robust COVID Response State } \\
\hline Low Response State $\times 20 / 4$ & $\begin{array}{l}-0.00221 \\
(0.00377)\end{array}$ & $\begin{array}{l}-0.00123 \\
(0.00641)\end{array}$ & $\begin{array}{l}-0.00536 \\
(0.00752)\end{array}$ & $\begin{array}{l}-0.00237 \\
(0.00300)\end{array}$ \\
\hline \multicolumn{5}{|l|}{ [COVID Cases] Low Risk State } \\
\hline Medium Risk State $\times 20 / 4$ & $\begin{array}{l}0.000964 \\
(0.00317)\end{array}$ & $\begin{array}{c}0.0119^{* *} \\
(0.00482)\end{array}$ & $\begin{array}{c}0.0119^{* *} \\
(0.00586)\end{array}$ & $\begin{array}{c}0.00207 \\
(0.00223)\end{array}$ \\
\hline High Risk State $\times 20 / 4$ & $\begin{array}{l}-0.00133 \\
(0.00297)\end{array}$ & $\begin{array}{l}0.0304^{* * *} \\
(0.00460)\end{array}$ & $\begin{array}{l}0.0286^{* * *} \\
(0.00555)\end{array}$ & $\begin{array}{c}0.00737^{* * *} \\
(0.00223)\end{array}$ \\
\hline \multicolumn{5}{|l|}{ [City] Central City } \\
\hline Outside Central City $\times 20 / 4$ & $\begin{array}{c}0.00499^{*} \\
(0.00294)\end{array}$ & $\begin{array}{r}-0.000871 \\
(0.00437)\end{array}$ & $\begin{array}{c}0.00352 \\
(0.00533)\end{array}$ & $\begin{array}{c}-0.00712^{* * *} \\
(0.00221)\end{array}$ \\
\hline Not in Metropolitan Area × 20/4 & $\begin{array}{l}-0.00198 \\
(0.00388)\end{array}$ & $\begin{array}{c}-0.0240^{* * *} \\
(0.00620)\end{array}$ & $\begin{array}{c}-0.0270^{* * *} \\
(0.00743)\end{array}$ & $\begin{array}{c}-0.00847^{* * *} \\
(0.00295)\end{array}$ \\
\hline Constant & $\begin{array}{l}0.0160^{* * *} \\
(0.00440)\end{array}$ & $\begin{array}{c}0.000346 \\
(0.00148)\end{array}$ & $\begin{array}{l}0.0187^{* * *} \\
(0.00497)\end{array}$ & $\begin{array}{c}0.00339 \\
(0.00280)\end{array}$ \\
\hline Observations & 78051 & 78051 & 78051 & 79002 \\
\hline$R^{2}$ & 0.015 & 0.123 & 0.107 & 0.008 \\
\hline
\end{tabular}

Robust standard errors in parentheses; ${ }^{*} p<0.10,{ }^{* *} p<0.05,{ }^{* * *} p<0.010$ 
non-participation. On the other hand, the number of newly confirmed Covid-19 cases leads to (or "Granger causes") more unemployment and non-employment, suggesting that people's voluntary reduction of economic activities out of fear is an important channel through which the pandemic hampers the economy. ${ }^{7}$

Table 2 shows the estimation result for the change between November 2019 and November 2020, 7 months into the recovery process.

Consistent with Figure 2, the differential effect of the pandemic on men and women's unemployment has all but disappeared by November. The impact on women's non-participation rate is larger than men's, but the magnitude is small.

Among minorities, only Blacks exhibit a larger shock to unemployment. Since Blacks were hit less than even whites in April, this shows that Blacks were the slowest to recover.

We also see that by November 2020, the difference in the impact across education groups and across age groups has evaporated, when industries and occupations are controlled for. The result that by November 2020 the impact on more educated and less educated workers was similar is consistent with Forsythe et al. (2021), which shows that labor market tightness has converged for college-educated and high-school workers.

Among industries, leisure/hospitalities have not recovered from the shock. There is not much of a pattern across occupations, except that service occupations still show a significantly higher unemployment rate from its November 2019 level.

Table 2 also shows that state-level policies do have some effect on employment outcomes in November. Perhaps not surprisingly, states that rolled back containment policies or implemented less restrictive policies had smaller year-on-year rise in unemployment in November than the states with more restrictive policies. Furthermore, state-wide infection rates in the preceding month is uncorrelated with employment outcomes. This suggests that the fear effect evident in April may not be operating as it once did, possibly because people have re-assessed infection risks or adopted other ways of mitigating the risk (e.g., wearing masks).

\section{Concluding Remarks}

The economic impact of the pandemic was unequal initially, but as of November 2020, there remains little difference in its employment impact across demographic and socioeconomic groups. Women lost more jobs than men initially, but the differential effect has disappeared by November 2020. Similarly, Hispanics and Asians were hit harder than Blacks and whites in April 2020, but both groups recovered quite rapidly, especially Hispanics. Blacks on the other hand experienced a smaller employment loss than all other racial groups

\footnotetext{
${ }^{7}$ This is consistent with evidence from other countries. See Aum et al. (2020a) for example.
} 
Table 2 - November

(1) (2) (3) (4)

Jobless Unemployment Furlough Unemployment Not in Labor Force

[Gender] Male

Female $\times 20 / 11$

$-0.00122$

(0.00291)

$0.00344^{* *} \quad 0.00213$

$(0.00175) \quad(0.00372)$

$0.00689^{* * *}$

$(0.00173)$

[Race] White

Black $\times 20 / 11$

$0.00900^{*}$

(0.00517)

0.00358

$0.0160^{* *}$

0.00152

Hispanic $\times 20 / 11$

0.00265

(0.00278)

$(0.00647)$

(0.00275)

(0.00384)

0.00275

0.00449

0.00208

0.00308

(0.00237)

$(0.00497)$

(0.00204)

$(0.00449)$

0.00537

0.00817

0.00132

(0.00331)

$(0.00616)$

(0.00307)

[Education] High or less

Some College $\times 20 / 11$

$\begin{array}{cccc}0.00555 & 0.00190 & 0.00828^{*} & 0.00183 \\ (0.00388) & (0.00238) & (0.00501) & (0.00222) \\ 0.00577 & -0.00386^{*} & 0.00111 & 0.000767 \\ (0.00403) & (0.00231) & (0.00511) & (0.00221)\end{array}$

[Age] Aged 20 to 35

Aged 36 to $50 \times 20 / 11$

$\begin{array}{llll}-0.00210 & -0.00196 & -0.000761 & -0.00114 \\ (0.00315) & (0.00183) & (0.00404) & (0.00174) \\ 0.00390 & -0.000395 & 0.00598 & -0.00321^{*}\end{array}$

Aged 51 to $65 \times 20 / 11$ 
$(0.00328) \quad(0.00203) \quad(0.00422) \quad(0.00194)$

[Industry] Public administration

Mining $\times 20 / 11$

Construction $\times 20 / 11$

Manufacturing $\times 20 / 11$

Wholesale and retail trade $\times 20 / 11$

Transportation and utilities $\times 20 / 11$

Information $\times 20 / 11$

Financial activities $\times 20 / 11$

Professional and business services $\times 20 / 11$

Educational and health services $\times 20 / 11$

Leisure and hospitality $\times 20 / 11$

$\begin{array}{cccc}0.0980^{* * *} & 0.0249 & 0.155^{* * *} & 0.0159 \\ (0.0285) & (0.0172) & (0.0356) & (0.0123) \\ & & & \\ 0.0159^{*} & 0.0104^{* *} & 0.0357^{* * *} & 0.0121^{* * *} \\ (0.00829) & (0.00475) & (0.0108) & (0.00433) \\ & & & \\ 0.00557 & 0.00464 & 0.0152^{*} & 0.0105^{* * *} \\ (0.00604) & (0.00348) & (0.00794) & (0.00399) \\ 0.00892 & 0.000520 & 0.0130 & 0.00457 \\ (0.00650) & (0.00341) & (0.00839) & (0.00456) \\ 0.00888 & 0.0145^{* * *} & 0.0289^{* * *} & 0.0106^{* *} \\ (0.00695) & (0.00498) & (0.00962) & (0.00527) \\ 0.0312^{* * *} & 0.0148^{* *} & 0.0597^{* * *} & 0.0119^{* *} \\ (0.0104) & (0.00669) & (0.0142) & (0.00536) \\ 0.00514 & 0.00279 & 0.00893 & 0.00691 \\ (0.00599) & (0.00327) & (0.00780) & (0.00429) \\ 0.00152 & 0.00481 & 0.0136^{*} & 0.0101^{* * *} \\ (0.00546) & (0.00320) & (0.00731) & (0.00374) \\ 0.00340 & 0.00124 & 0.00487 & 0.00818^{* *} \\ (0.00470) & (0.00270) & (0.00624) & (0.00369) \\ 0.0461^{* * *} & 0.0298^{* * *} & 0.102^{* * *} & 0.0138^{* * *} \\ (0.00805) & (0.00526) & (0.0105) & (0.00499) \\ & & & \end{array}$


Other services $\times 20 / 11$

Agriculture, forestry, fishing, and hunting $\times 20 / 11$

Armed Forces $\times 20 / 11$

[Occupation] Management, business, and financial

Professional and related $\times 20 / 11$

Service $\times 20 / 11$

Sales and related $\times 20 / 11$

Office and administrative support $\times 20 / 11$

Farming, fishing, and forestry $\times 20 / 11$

Construction and extraction $\times 20 / 11$

Installation, maintenance, and repair $\times 20 / 11$

Production $\times 20 / 11$

$\begin{array}{cccc}0.0220^{* * *} & 0.00902^{* *} & 0.0323^{* * *} & 0.00922^{*} \\ (0.00777) & (0.00441) & (0.00994) & (0.00495) \\ & & & \\ 0.00995 & 0.00853 & 0.0164 & 0.0178^{*} \\ (0.0130) & (0.0135) & (0.0187) & (0.00993) \\ & & & 0.169 \\ -0.377 & -0.00396 & 0.00888 & (0.181)\end{array}$

0.000524

(0.00358)

0.00113

0.00264

$(0.00208)$

$(0.00459)$

$-0.00109$

0.00715

$(0.00545)$

$0.00880^{* * *}$

$0.0224^{* * *}$

$(0.00193)$

$-0.000130$

(0.00587)

(0.00320)

(0.00686)

$0.00579^{* *}$

(0.00293)

$$
\begin{gathered}
0.00164 \\
(0.00316)
\end{gathered}
$$

0.00732

0.00417

(0.00740)

(0.00347)

0.000552

(0.00482)

$-0.00197$

0.00201

(0.00257)

(0.00617)

0.00161

(0.00292)

$-0.0113$

(0.0247)

$-0.0265$

(0.0224)

$-0.0332$

(0.0336)

0.00582

(0.0110)

$-0.0148^{*}$

(0.00892)

0.00325

$-0.00600$

(0.0119)

0.00311

(0.00597)

$-0.00408$

0.0111

(0.00922)

(0.00378)

(0.00755)

(0.00366)

0.00508

(0.00399)

$-0.00112$

$0.0161^{*}$

0.00396 


$\begin{array}{cccc}(0.00701) & (0.00503) & (0.00972) & (0.00363) \\ 0.0137^{*} & 0.000589 & 0.0238^{* *} & 0.0108^{* *} \\ (0.00747) & (0.00423) & (0.00957) & (0.00450)\end{array}$

[Policy] Robust COVID Response State

Rapid Rollback State $\times 20 / 11$

Low Response State $\times 20 / 11$

[COVID Cases] Low Risk State

Medium Risk State $\times$ 20/11

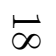

High Risk State $\times 20 / 11$

[City] Central City

Outside Central City $\times 20 / 11$

Not in Metropolitan Area $\times 20 / 11$

Constant

Observations
$R^{2}$

Robust standard errors in parentheses; ${ }^{*} p<0.10,{ }^{* *} p<0.05,{ }^{* * *} p<0.010$

$\begin{array}{lccc}-0.00398 & -0.00678^{* * *} & -0.00985^{* *} & 0.00205 \\ (0.00321) & (0.00175) & (0.00405) & (0.00186) \\ -0.0114^{* *} & -0.00244 & -0.0117^{* *} & 0.00495^{*} \\ (0.00469) & (0.00267) & (0.00593) & (0.00255)\end{array}$

$\begin{array}{cccc}0.00563^{*} & -0.00155 & 0.00351 & 0.00118 \\ (0.00311) & (0.00184) & (0.00397) & (0.00179) \\ 0.00443 & -0.000111 & -0.000854 & -0.00191 \\ (0.00387) & (0.00227) & (0.00493) & (0.00234)\end{array}$

$-0.00692^{*}$

$-0.000904$

$-0.0100^{* *}$

$-0.0000606$

$(0.00308)$

(0.00180)

(0.00393)

(0.00172)

$-0.0144^{* * *}$

$-0.00712^{* * *}$

$-0.0262^{* * *}$

$-0.00357$

(0.00442)

(0.00266)

(0.00547)

(0.00259)

$0.0198^{* * *}$

$-0.00167$

$0.0202^{* * *}$

$0.0128^{* * *}$

(0.00452)

(0.00144)

(0.00529)

(0.00287)

$80970 \quad 80970 \quad 81734$

$0.015 \quad 0.034$

0.005 
at first, but are suffering from a slow recovery later on. These results remain even after controlling for all other factors, including industries, occupations and state-level infection rates and policies.

Workers without a college degree were hit worse than college-educated workers in April 2020, but by November 2020, this difference across education groups all but vanished. Likewise, younger workers lost more jobs initially, but no systematic difference remains in the pandemic's employment impact across age groups.

Thus, while it still remains to be seen, at least some of the unequal effects seem to have been short-lived. Our findings call for a careful investigation of the mechanism through which different demographic and socio-economic groups were affected unequally by the pandemic. 


\section{References}

Adams-Prassl, A., T. Boneva, M. Golin, and C. Rauh (2020a). Furloughing. Fiscal Studies $41(3), 591-622$.

Adams-Prassl, A., T. Boneva, M. Golin, and C. Rauh (2020b). Inequality in the impact of the coronavirus shock: Evidence from real time surveys. Journal of Public Economics 189, 104245 .

Alon, T., M. Doepke, J. Olmstead-Rumsey, and M. Tertilt (2020, April). The Impact of COVID-19 on Gender Equality. Working Paper 26947, National Bureau of Economic Research.

Aum, S., S. Y. T. Lee, and Y. Shin (2020a, May). Covid-19 doesn't need lockdowns to destroy jobs: The effect of local outbreaks in Korea. Working Paper 27264, National Bureau of Economic Research.

Aum, S., S. Y. T. Lee, and Y. Shin (2020b, October). Who should work from home during a pandemic? The wage-infection trade-off. Working Paper 27908, National Bureau of Economic Research.

Blundell, R., M. Costa Dias, R. Joyce, and X. Xu (2020). Covid-19 and inequalities. Fiscal Studies 41(2), 291-319.

Cajner, T., L. D. Crane, R. A. Decker, J. Grigsby, A. Hamins-Puertolas, E. Hurst, C. Kurz, and A. Yildirmaz (2020, May). The U.S. labor market during the beginning of the pandemic recession. Working Paper 2d7159, NBER.

Couch, K. A., R. W. Fairlie, and H. Xu (2020). Early evidence of the impacts of covid-19 on minority unemployment. Journal of Public Economics 192, 104287.

Cowan, B. W. (2020, June). Short-run effects of covid-19 on u.s. worker transitions. Working Paper 27315, National Bureau of Economic Research.

Forsythe, E., L. B. Kahn, F. Lange, and D. Wiczer (2021). Searching, recalls, and tightness: An interim report on the covid labor market. Manuscript.

Gezici, A. and O. Ozay (2020, August). How race and gender shape covid-19 unemployment probability. PERI Working Papers 521, Univeristy of Massachusetts Amherst. 
Hale, T., T. Atav, L. Hallas, B. Kira, T. Phillips, A. Petherick, and A. Pott (2020, December). Variation in us states' responses to covid-19. BSG Working Paper Series 2020/034, Blavatnik School of Government, University of Oxford.

Hall, R. E. and M. Kudlyak (2020, October). Unemployed with jobs and without jobs. Working Paper 27886, National Bureau of Economic Research.

Hensvik, L., T. L. Barbanchon, and R. Rathelot (2020). Which jobs are done from home? Evidence from the American Time Use Survey. Centre for Economic Policy Research Discussion Papers.

Lee, S. Y. T., Y. Shin, and D. Lee (2015, November). The option value of human capital: Higher education and wage inequality. Working Paper 21724, National Bureau of Economic Research.

Montenovo, L., X. Jiang, F. L. Rojas, I. M. Schmutte, K. I. Simon, B. A. Weinberg, and C. Wing (2020, May). Determinants of disparities in covid-19 job losses. Working Paper 27132, National Bureau of Economic Research. 